\title{
Green Buildings and Sustainable Development
}

\author{
Seyed Hossein Abedian Kalkhoran, Dr.S.S.Pimplikar \\ Me Civil (C\&M) Student Mit College,Pune,India \\ Professor \& Head Of Civil Department Mit College, Pune, India
}

\begin{abstract}
Man has constructed buildings for working, living and leisure since the advent of civilization. Over the centuries, many architectural styles evolved and buildings became more complex. During the last hundred years or so, the energy consumed in buildings for lighting, heating and cooling has increased enormously. This, in turn, has led to a sharp increase in the consumption of fossil fuels and electricity derived from them.

As the world faces increasing environmental and resource related problems, it is imperative that we design and construct buildings that would be energy efficient.

A green building, also known as a sustainable building, is a structure that is designed, built, renovated, operated, or reused in an ecological and resource-efficient manner. Green buildings are designed to meet certain objectives such as protecting occupant health; improving employee productivity; using energy, water, and other resources more efficiently; and reducing the overall impact to the environment.

The paper attempts to highlight some of the methods to develop a green building or convert our existing buildings into green buildings.
\end{abstract}

Keywords: Sustainable, green buildings, energy saving.

\section{Introduction}

Buildings account for one-sixth of the world's fresh water withdrawals, one-quarter of its wood harvest, and two-fifths of its material and energy flows. Building "green" is an opportunity to use our resources efficiently while creating healthier buildings that improve human health, build a better environment, and provide cost savings.

\section{Concept Of A Green Building}

\section{What Makes a Building Green?}

A green building, also known as a sustainable building, is a structure that is designed, built, renovated, operated, or reused in an ecological and resource-efficient manner. Green buildings are designed to meet certain objectives such as protecting occupant health; improving employee productivity; using energy, water, and other resources more efficiently; and reducing the overall impact to the environment

\section{What Are the Benefits of Green Buildings?}

A green building may have high initial cost but saves through lower operating costs over the life of the building. Some benefits, such as improving occupant health, comfort, productivity, reducing pollution and landfill waste are not easily quantified. Consequently, they are not adequately considered in cost analysis.

The concept of a green building can be achieved by taking care of the following points.

1. Proper selection of site

2. Efficient design of a building

3. Use of proper building materials

4. Proper management of energy

5. Water management and efficienc

6. Building healthier home

7. Recycling of old building materials

8. Reducing Energy Consumption

\section{Proper Selection of Site}

Start by selecting a site well suited to take advantage of mass transit. Protect and retain existing landscaping and natural features. Select plants that have low water and pesticide needs, and generate minimum plant trimmings. Use of compost will save water and time.

How it can be achieved:

$>$ Maximize erosion and sedimentation control. 
$>$ Minimize site disturbance.

$>$ Maximize planted areas.

$>$ Reduce heat islands.

$>$ Reduce or eliminate use of pesticides.

$>$ Rely on indigenous, dry or xeriscape planting. Maintain existing plants on site to reduce costs.

$>$ Implement seasonal plant and soil maintenance schedule to maintain healthy soil and landscaping.

$>$ Maximize stormwater runoff.

$>$ Reduce water use with water efficient irrigation systems and local vegetation.

\section{Efficient Design Of A Building}

Recent studies reveal that buildings with good overall environmental quality can reduce the rate of respiratory disease, allergy, asthma, sick building symptoms, and enhance worker performance.

An efficient design of a building implies an optimal utilization of space, leaving no waste, and thereby optimizing the available resources. The orientation of a building to the sun and wind, the size and scale of spaces, the balance of the solids and voids of a building can favourable influence not only the living comforts but also the resource consumption and the energy intake.

For example, the sharing of the walls between adjoining buildings not only reduces the consumption of the construction materials but also cuts down the surface exposure, making the building less vulnerable to the effect of external climatic forces. Splitting the total built-up are in several floors also gives the same benefits. Varying the levels and volumes in a space reduces the energy consumption by nearly 10 percent. Providing a floor above reduces the energy consumption by 20 percent and sharing two sides of a building with another building can bring it down to the order of 40 to 50 percent.

The orientation of the building with respect to the sun and the wind directions can not only enhance the comfort level of the occupants but also bring down the power consumption drastically. Provide adequate ventilation and a high-efficiency, in-duct filtration system. Heating and cooling systems that ensure adequate ventilation and proper filtration can have a dramatic and positive impact on indoor air quality.

\section{Use Of Proper Materials}

Choose construction materials and interior finish products with zero or low emissions to improve indoor air quality, high recyclability, durability, longevity, and local production and possibility of reuse. Such products promote resource conservation and efficiency.

Many building materials and cleaning/maintenance products emit toxic gases, such as volatile organic compounds (VOC) and formaldehyde. These gases can have a detrimental impact on occupants' health and productivity.

Prevent indoor microbial contamination through selection of materials resistant to microbial growth, provide effective drainage from the roof and surrounding landscape, install adequate ventilation in bathrooms, allow proper drainage of air-conditioning coils, and design other building systems to control humidity.

How it can be achieved:

$>$ Select materials with longest useful service life.

$>$ Select materials that deteriorate minimally under installed conditions, exposures, and uses.

$>$ Select materials with surfaces that require minimal or no refinishing or resurfacing.

$>$ Select materials with protective coating requirements that do not involve frequent application of toxic or odorous components for materials that require surface renewal or protection

$>$ Select materials that can be re-used after their service life in this building.

$>$ Select materials that can be recycled at the end of their useful lives for materials that cannot be re-used.

> Use resource efficient materials; consider energy use over life cycle of material including harvesting, mining, manufacturing, transport, installation, use, operations, recycling and disposal.

$>$ Where possible, select materials harvested and manufactured regionally, within a 500-mile radius of the project site.

$>$ Select materials that create minimal or no damage to natural habitats and natural environment.

$>$ Select materials that can be easily refinished, repaired or refurbished to extend their useful life.

$>$ Avoid materials that emit greenhouse gases

$>$ Avoid materials that contain ozone-depleting chemicals (e.g. CFCs or HCFCs).

$>$ Avoid materials that emit potentially harmful volatile organic chemicals (VOCs)

$>$ Employ construction practices that minimize dust production and combustion by-products.

$>$ Avoid materials that can leach harmful chemicals into ground water; do not allow potentially harmful chemicals to enter sewers or storm drains.

$>$ Minimize noise generation during construction; screen mechanical equipment to block noise. 


\section{Proper Management Of Energy}

Passive design strategies can dramatically affect building energy performance. These measures include building shape and orientation, passive solar design, and the use of natural lighting. Develop strategies to provide natural lighting. Studies have shown that it has a positive impact on productivity and well being.

Install high-efficiency lighting systems with advanced lighting controls. Include motion sensors tied to dimmable lighting controls. Task lighting reduces general overhead light levels. Use a properly sized and energy-efficient heat/cooling system in conjunction with a thermally efficient building shell. Maximize light colors for roofing and wall finish materials; install high R-value wall and ceiling insulation; and use minimal glass on east and west exposures. Minimize the electric loads from lighting, equipment, and appliances. Consider alternative energy sources

How it can be achieved:

$>$ Solar energy can be utilsed for various purposes right from cooking with solar cookers, heating of water with solar water heaters, providing solar operated lights in open areas like gardens as well as the frequently used areas like kitchen, wash basin and drawing room etc.

$>$ Use daylight as the primary lighting source in classrooms and supplement with integrated and energyefficient electrical lighting systems.

$>$ Where appropriate, use thermal storage strategies such as thermal mass of building or ground to minimize total energy consumption.

$>$ Design mechanical systems for efficient operation throughout the typical operating range, from minimum to peak load.

\section{Water Management And Efficiency}

Water is another precious resource often in short supply and yet irresponsibly wasted. Rain is the primary source of fresh water and rivers, lakes, ponds, wells etc are the secondary sources of water. Cherapunji is a place known for highest rainfall. Inspite of this fact, it faces water scarcity and therefore has drinking water problems. It is therefore important that we store as much water as possible from the rainwater as the problem is not with the adequacy of the resource but with its proper management.

Before urbanization took place, the rain water used to flow over the streets or plain grounds in villages and was stored in open ponds, wells lakes etc or in the form of underground storage tanks of individual houses as found in some of the ancient architecture. It was a method of creatively integrating rain water with architecture. It is sad but true that such traditional practices are not being followed and the wisdom of our forefathers has literally drained off with the passing time. Today we consider ourselves to be more advanced in technology, but proper integration of technology and knowledge can change the scenario.

For the city of Vadodara, the average annual rainfall is $900 \mathrm{~mm}$. If this water falling on the terrace/roof of an average sized house is collected and reutilized, it can fulfill the requirements of a family of four members for approximately a period of two months. In case if it is not utilized, it can help in recharging the local aquifer and thus enhancing the ground water.

Water recycling after treating naturally the waste water through aquatic weeds or plant material or fish or by passing it through the traditional tier filter system is safe enough for gardening or flushing of toilets or other such uses.

How water efficiency can be achieved:

* Reduce the use of municipally supplied potable water.

$>$ Maintain natural aquifer conditions.

$>$ Consider roof water or groundwater collection system.

$>$ Consider gray water collection system for irrigation systems.

$>$ Design for dual plumbing to use recycled water for toilet flushing or a gray water system that recovers rainwater or other non-potable water for site irrigation.

> Minimize wastewater by using ultra low-flush toilets, low-flow shower heads, and other water conserving fixtures.

$>$ Use recirculating systems for centralized hot water distribution.

$>$ Install point-of-use hot water heating systems for more distant locations.

> Meter the landscape separately from buildings. Use micro-irrigation (which excludes sprinklers and highpressure sprayers) to supply water in non-turf areas.

$>$ Use state-of-the-art irrigation controllers and self-closing nozzles on hoses. 


\section{Building Healthier Homes}

Eco-friendly construction can not only help to create a better outdoor environment, it can also help to build a healthier indoor environment. Conventional building materials and methods have been linked to a wide range of health problems. Chemical pollutants from paints, solvents, plastics and composite timbers, along with biological pollutants such as dust mites and moulds are known to cause symptoms such as asthma, headaches, depression, eczema, palpitations and chronic fatigue syndrome. Green buildings eliminate these problems through good ventilation design, breathable walls, and the use of natural, non-toxic products and materials.

There are many good reasons why we should use eco-friendly construction methods and materials. It can improve the health of our planet, and the health of our own lives. It also supports local business and helps strengthen the local economy, which in turn helps to build our communities into vibrant, prosperous and desirable places to live.

\section{Recycling And Reuse Of Old Building Materials}

Construction and demolition $(C \& D)$ materials account for almost 22 percent of the waste stream. Many of these materials can be reused or recycled, thus prolonging our supply of natural resources and potentially saving money in the process.

Common C\&D materials include drywall, metals, masonry (brick, concrete, etc.), carpet, plastic, pipe, rocks, dirt, paper, cardboard, or green waste related to land development. Of these, metals are the most commonly recycled material.

At the end of a building's life, demolition generates large amounts of materials that can be reused or recycled, principally wood, concrete and other types of masonry, and drywall. Rather than demolish an entire building, consider "deconstructing" all or part of the structure. Deconstruction is the orderly dismantling building components for reuse or recycling. In contrast to demolition, where buildings are knocked down and materials are either landfilled or recycled, deconstruction involves carefully taking apart portions of buildings or removing their contents with the primary goal being reuse. It can be as simple as stripping out cabinetry, fixtures, and windows, or as involved as manually taking apart the building frame.

\section{Reducing Energy Consumption}

With the inevitability of declining fossil fuels, and the threat of global climate change, reducing our energy consumption is an essential survival strategy. Choosing to build green saves energy. The low embodied energy of green products ensures that very little energy went into their manufacture and production, with a direct reduction in carbon emissions. Eco friendly design methodology can further reduce energy consumption by minimising energy inputs for heating, cooling and light, and incorporating energy efficient appliances. Saving energy for the occupant also saves money - an issue that will become increasingly important as the cost of fossil fuels inevitably rises in the near future.

\section{Conclusion}

Application of the new technologies, which are combination of traditional energy and modern science, can provide a means for reducing the demand on our energy supply system by buildings constructed throughout the country, while at the same time providing a high level of indoor-living-comfort. Such a modern approach to blend the modern science with traditional knowledge helps to come up with a structure that is pleasant and at the same time aesthetically attractive as well as climatically attuned to its surroundings for providing comfort to its occupants.

An energy-efficient building balances all aspects of energy use in a building including energy required for lighting, space-conditioning, and ventilation. It can generally achieved by providing an optimized mix of passive solar design strategies, energy-efficient equipments, and renewable sources of energy, besides the use of materials with low embodied energy. If well designed energy efficient techniques are applied to just $10 \%$ of the buildings constructed in cities every year, it is estimated to make enough savings to light 20 million rural households in India. An energy-efficient building may require about 20 to 30\% higher initial investment (per square meter), as compared to that of a non-energy efficient building, but offer substantial savings in energy consumption. Due to this additional cost, modern techniques are not receiving proper attention in most of our urban plans and construction activities, but for a reasonably big building (about 10000 -squaremetre plinth area), the energy consumption in such a modern building may come down by about $40 \%$. With a life-expectancy of 30 years (and with an electricity tariff rate of 6 rupees $/ \mathrm{kWh}$, and a discount rate of $10 \%$ ), the additional investment made can easily be recovered in a shot span of time. 


\section{Acknowledgment}

I would like to express my very great appreciation to Dr.S.S.Pimplikar for his valuable and constructive suggestions during the planning and development of this research work. His willingness to give his time so generously has been very much appreciated.

Special thanks should be given to Dr. D. M. KONDAP, my research project supervisor for his professional guidance and valuable support and and constructive recommendations on this project.

[1] brwillis - 2012 - digital.library.txstate.edu

\section{References}

[2] cj kibert - 2012 - books.google.com

[3] mrossi, t lent - designing the 21 st century hospital, 2006 - chemicalspolicy.net

[4] report 22: sustainable raw materials: construction and demolition waste-state-of-the-art report of rilem technical committee 165-srm

[5] http://www.calrecycle.ca.gov/greenbuilding/basics.htm

[6] http://www.sustainablebuild.co.uk/ecofriendlyconstructionmethodsmaterials.html

[7] http://www.magaddinoarchitecture.com/sustainable/ 